\title{
Análise da evolução do desmatamento na região amazônica através de imagens de satélite
}

Cayo Guimarães Machado, Camila Souza dos Anjos Lacerda, Carolina Gil Garcia, Débora Paula Simões

https://doi.org/10.4322/mp.978-65-991393-8-3.c2

\section{Resumo}

Com o crescente avanço da agricultura e pecuária, o desmatamento está se tornando comum, configurando-se em um dos graves processos de degradação florestal. $\mathrm{O}$ mapeamento das informações espaciais sobre a cobertura vegetal é um recurso muito utilizado para evidenciar os padrões de uso e ocupações destes espaços, referente à evolução da paisagem no tempo e no espaço. Neste estudo, utilizaram-se técnicas de sensoriamento remoto e detecção de mudanças em imagens, com o objetivo de realizar a análise multitemporal do desmatamento ambiental no município de Monte Negro, em Rondônia, entre os anos de 2013 e 2019. As imagens foram adquiridas pelo catálogo de imagens do USGS (United States Geological Survey) e do INPE (Instituto Nacional de Pesquisas Espaciais), e foram obtidas pelo sensor OLI do satélite LandSat-8. Realizado o processamento das imagens, executou-se a classificação das mesmas com base nas classes majoritárias, disponibilizadas pelo Mapbiomas Brasil: Floresta, Formação natural não floresta, Agropecuária, Área não vegetada e Corpo d'água. No período em análise, observou-se que $9 \%$ da área total do município sofreu desflorestamento. $92,64 \%$ do desflorestamento total do município foram através da transição de florestas para agropecuária. Além disso, a classificação do ano de 2013 da área estudada apresentou uma exatidão global de 72,9\% de um total avaliado de 701 pontos gerados aleatoriamente sobre a área de estudo, comparados ao mapa de referência do Mapbiomas. O trabalho limitou-se a realizar a validação somente do ano de 2013, pois os dados de 2019 não foram disponibilizados pelo Mapbiomas até a finalização deste trabalho.

Palavras-chave: desflorestamento, detecção de mudanças, geoprocessamento, Mapbiomas, sensoriamento remoto.

\section{Introdução}

Em 1953, foi criada a Amazônia Legal Brasileira, definida como o território federal que abrange grandes áreas de matas de transição e de cerrado, fora do domínio equatorial amazônico. Sua criação atende a necessidade do governo em planejar e promover o desenvolvimento ordenado da região, de acordo com a Superintendência de Desenvolvimento da Amazônia - SUDAM [1]. A região da Amazônia Legal tem sofrido um intenso processo de desmatamento ambiental, ligado principalmente à atividade pecuária, a agricultura em larga escala e a agricultura de corte e queima. As atividades humanas realizadas no território sobre a substituição da cobertura vegetal têm se demonstrado um problema que causa preocupação na sociedade [2]. Com isso, o desflorestamento na Amazônia tem aumentado a demanda de mapeamento como 
forma de monitoramento do bioma, tornando-se indispensável a utilização de técnicas como o sensoriamento remoto e o geoprocessamento. No contexto da geração de mapeamentos sistemáticos acompanhados de estimativas periódicas da taxa de desmatamento na Amazônia brasileira, o trabalho de maior alcance vem sendo desenvolvido pelo Instituto Nacional de Pesquisas Espaciais (INPE) desde 1988, a partir da análise das imagens do satélite norte americano Landsat ou similares, como forma de combater o desmatamento e a degradação ambiental [3]. Atualmente, com a união da disponibilidade das imagens de sensores orbitais de domínio público e a possibilidade de processamento desses dados em nuvens de computadores, foi possível o surgimento de novos projetos de mapeamento do uso e cobertura do solo e de monitoramento do desmatamento ambiental em escala regional e global. Nesse contexto, surgiram plataformas como o Projeto de Mapeamento Anual da Cobertura e Uso do Solo do Brasil (MapBiomas), o Projeto de Monitoramento do Desmatamento da Floresta Amazônica Brasileira por Satélite (PRODES), o Sistema de Alerta de Desmatamento (SAD), o Sistema de Detecção de Desmatamento em Tempo Real (DETER), que visam quantificar anualmente o desmatamento e as mudanças no uso e ocupação do solo do bioma Amazônia e de outros biomas.

Diante das preocupações com desmatamento, em especial na Amazônia Legal, e do potencial das técnicas de geoprocessamento e sensoriamento remoto no levantamento de dados nesse contexto, o presente estudo visa utilizar de tais técnicas para avaliar a evolução do desmatamento ambiental entre os anos de 2013 e 2019, delimitada a um município do estado de Rondônia: município de Monte Negro.

\section{Material e Métodos}

Inicialmente, foi caracterizada a área de estudo do presente trabalho, que compreende o município de Monte Negro, localizado na Unidade Federativa de Rondônia. Ele possui uma extensão territorial de aproximadamente $1.931 \mathrm{~km}^{2}$, e está situado entre as coordenadas geográficas de $10^{\circ} 02^{\prime} 2,94^{\prime \prime} \mathrm{S}$ e $10^{\circ} 29^{\prime} 33,25^{\prime \prime} \mathrm{S}$ de latitude e $63^{\circ} 06^{\prime}$ $48,34^{\prime \prime} \mathrm{O}$ e $63^{\circ} 35^{\prime} 48,02^{\prime \prime} \mathrm{O}$ de longitude de Greenwich. A área do estudo é parte integrante da Amazônia Legal Brasileira, portanto, o bioma do município é Amazônia [4]. A Figura 1 demonstra todos os processos realizados através de um fluxograma, associando cada etapa realizada com os softwares trabalhados.

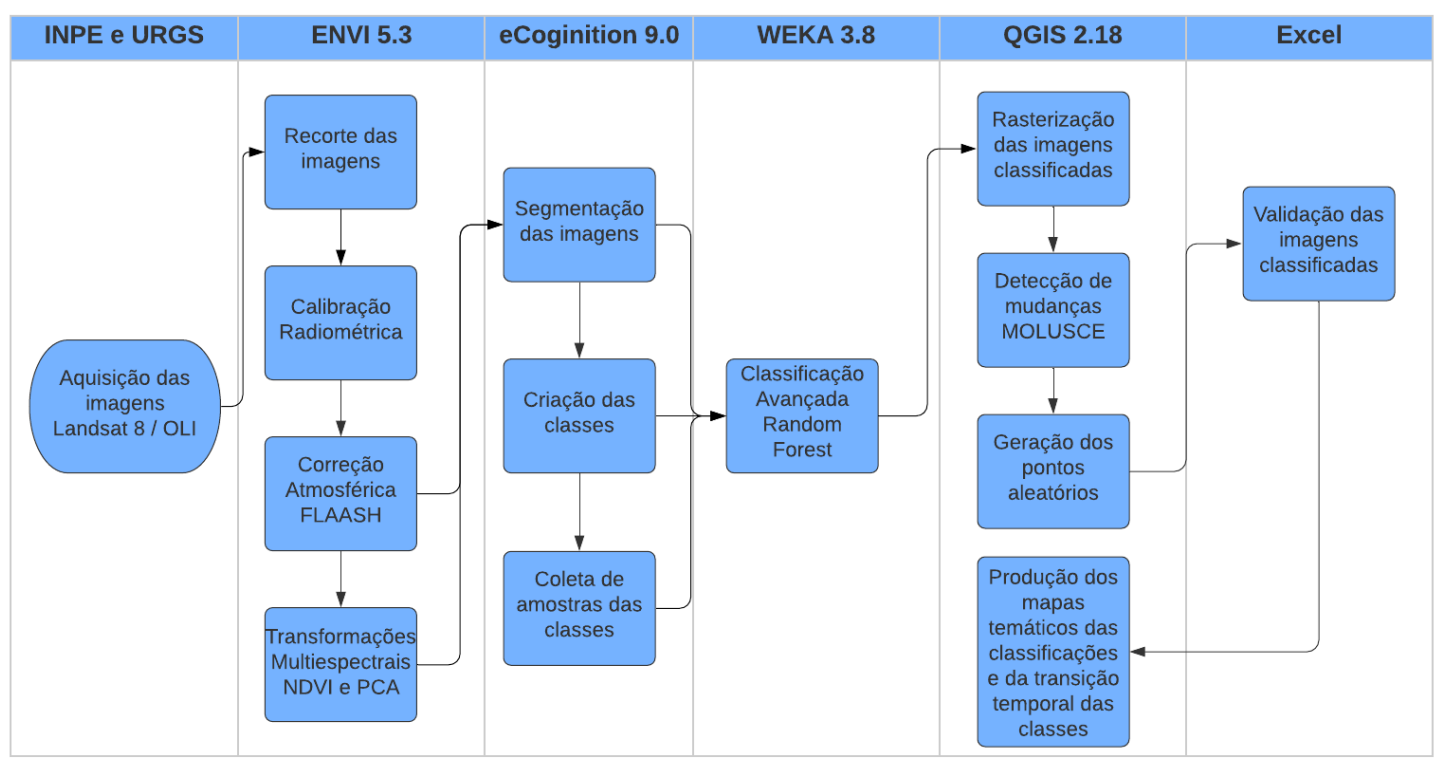

Figura 1. Fluxograma dos processos realizados na metodologia. 
Definida então a área de estudo, iniciou-se a aquisição das imagens, através dos mecanismos de pesquisa on-line como Earth Explorer (USGS, 2019) e a Divisão de Geração de Imagens (INPE, 2019), na qual para este trabalho, foi estabelecido o ano inicial e final da análise temporal. A disponibilização das imagens referentes ao sensor OLI do satélite Landsat-8, iniciou em fevereiro de 2013, portanto, a imagem mais antiga da análise é do ano de 2013. Já a imagem mais recente da análise, disponibilizada pelo mesmo sensor e satélite (OLI/Landsat-8), submete-se ao ano de 2019. A época definida para a realização deste estudo foi o mês de julho, escolhido por ser um período com menor índice pluviométrico. As imagens OLI/Landsat-8 possuem uma resolução espacial 30 metros para as bandas multiespectrais e 15 metros para a banda pancromática, contendo um total de 9 bandas espectrais, das quais 2 dessas não foram utilizadas no presente estudo (Pancromática e Cirrus).

Com as imagens já adquiridas, iniciou-se o processo de recorte das imagens. Este recorte baseou-se no arquivo vetorial (polígono) disponibilizado pelo IBGE, do limite do município de Monte Negro, utilizando a ferramenta de recorte disponibilizada pelo software ENVI 5.3. Em seguida, foram realizados os pré-processamentos das imagens, como calibração radiométrica, a correção atmosférica e as transformações multiespectrais NDVI e PCA. Iniciando pela calibração radiométrica, a qual serve para calibrar e/ou converter os dados registrados pelos sensores em quantidades físicas passíveis de serem correlacionadas a parâmetros biofísicos ou geofísicos de objetos, foram aplicadas as configurações de calibração baseadas na correção atmosférica FLAASH, empregando seguintes parâmetros: os números digitais serão convertidos em radiância de acordo com o padrão do FLAASH, o entrelaçamento das bandas é do tipo BIL, os dados de saída são do tipo ponto flutuante, e o fator de escala de 0,1 . Finalizado o processo de calibração radiométrica, é gerada uma imagem radiância na qual se percebe visualmente que o nível de iluminação foi melhorado, sendo possível distinguir os objetos de maneira mais fácil. Após esse procedimento realizado para as duas imagens, elas estão aptas para a realização da correção atmosférica. $O$ procedimento de correção atmosférica neste trabalho, como foi citado, utilizou à ferramenta do modelo FLAASH do software ENVI 5.3, onde os valores físicos de radiância serão convertidos para reflectância de superfície, baseando-se nos parâmetros inseridos no processo de calibração radiométrica. Essa ferramenta de correção atmosférica requer alguns parâmetros referentes ao sensor utilizado e a geolocalização da cena, como: altitude do sensor, altitude média do terreno imageado, coordenadas do centro da cena, tamanho do pixel e data e hora do voo. Além disso, a ferramenta FLAASH necessita de informações sobre o modelo atmosférico da área em estudo, como a época (mês) e latitude de captura da cena, que está relacionado ao vapor d'água contido na atmosfera local, e o modelo aerossol, representado em áreas que não são fortemente afetadas por fontes urbanas ou industriais. Por utilizar imagens referentes ao mesmo mês de julho (época), e por ter uma latitude média de $10^{\circ} \mathrm{S}$ (geolocalização), o modelo escolhido foi o Tropical, conforme o guia do software. Por fim, resultou-se em novas imagens com valores de reflectância de superfície, a qual será utilizada para futuros processos. A seguir, foram realizadas as transformações multiespectrais com a finalidade de realçar as características dos alvos, permitindo separar melhor os elementos presentes na imagem. O procedimento para extração das Componentes Principais, do inglês Principal Component Analysis (PCA), e do Índice de Vegetação por Diferença Normalizada, do inglês Normalized Difference Vegetation Index (NDVI) das imagens foi realizado também no software ENVI 5.3. Primeiramente, realizou-se a transformação multiespectral das Componentes Principais nas duas imagens (2013 e 2019), na qual se inserem as imagens obtidas da correção atmosférica, resultando em 2 novas cenas. Após as PCAs, iniciou-se o procedimento de extração do índice de vegetação, utilizando a ferramenta de transformação multiespectral NDVI, onde se inseriram as imagens resultantes da correção atmosférica. $O$ Índice de Vegetação por Diferença 
Normalizada (NDVI) [5] (Equação 1), que visa realçar diferenças espectrais entre a vegetação e outros alvos, utilizando a razão entre as bandas do NIR (Infravermelho Próximo) e Red (Vermelho).

$$
\mathrm{NDVI}=\frac{(\mathrm{NIR}-\mathrm{Red})}{(\mathrm{NIR}+\mathrm{Red})}
$$

Inicialmente, deve-se selecionar o sensor utilizado na captura das cenas e o número da posição das bandas do vermelho e do infravermelho próximo, resultando em uma imagem com a vegetação realçada em relação a outros objetos. Em posse das imagens já calibradas e corrigidas, e com suas respectivas transformações multiespectrais contendo informações necessárias sobre a vegetação, deu-se início a segmentação das imagens, que tem por objetivo agrupar os pixels contíguos que contenham a mesma resposta espectral do objeto ao sensor. Utilizando-se do software eCognition para segmentar e coletar as amostras de treinamento das classes, foram aplicados dois algoritmos para realização das segmentações, sendo eles por multirresolução e por diferença espectral. Primeiramente, foi utilizado o algoritmo de multirresolução para a geração dos segmentos. Neste algoritmo, definiuse um peso para os critérios de homogeneidade dos pixels contíguos, sendo eles forma e compacidade, em que foi definido o peso de 0,2 para forma e 0,7 para compacidade. Após esse procedimento, definiu-se como 50 o valor do parâmetro de escala das regiões homogêneas, resultando um elevado número de segmentos gerados. Posteriormente, no algoritmo de diferença espectral, utilizado para auxiliar a união dos segmentos contíguos que possuem resposta espectral semelhante, definiuse que as camadas do Coastal Aerosol, PCA 5 e PCA 6 teriam peso 0,5, a camada PCA 7 teria peso 0 e as demais camadas (Blue, Green, Red, NIR, SWIR 1, SWIR 2, PCA 1, PCA 2, PCA 3, PCA 4 e NDVI) teriam peso 1. Logo, o parâmetro de máxima diferença espectral foi definido em 100, resultando em um menor número de segmentos gerados, observando-se que o número de segmentos gerados pelo algoritmo de multirresolução foi relativamente grande. Os features relacionados para a extração de atributos referente a cada segmento foram:

- Mediana da moda do NDVI e PCA1;

- Média das bandas Red, Blue, Green, NIR e PCAs;

- Nome das classes;

- Brilho;

- Máxima diferença espectral;

Após segmentar as imagens, iniciou-se o processo de criação das classes que foram utilizadas nas classificações. As classes adotadas tiveram como base as descrições de classes da área de estudo no Mapbiomas. De acordo com a legenda da plataforma on-line, as classes são subdivididas em 3 níveis e biomas. Para este trabalho, utilizaram-se somente as classes majoritárias do Mapbiomas, sendo estas: Floresta, Formação natural não florestal, Agropecuária, Área não vegetada e Corpo d'água. Essas amostras de treinamento das classes foram coletadas observando o mapa de referência através do Mapbiomas, aplicando o layer ESRI World Imagery, que utiliza imagens do Landsat-8 fusionadas, ou seja, com a resolução espacial melhorada para 15 metros. Finalizada a coleta de amostras das classes para as duas cenas, extraíram-se os atributos citados acima para as duas imagens juntamente com as amostras coletadas. Por fim, geraram-se dois arquivos no formato shapefile, dois arquivos no formato CSV e dois arquivos pertencentes ao shapefile no formato DBF, referentes a cada imagem. Um dos arquivos contém apenas as amostras de treinamento coletadas, e o outro contém todos os segmentos da imagem. Os arquivos 
CSV (As tabelas de atributos das camadas de nuvens de pontos geradas) foram utilizados posteriormente no WEKA 3.8 para a realização da classificação, por ser o arquivo de entrada do software, onde será posteriormente transformado no formato ARFF para correlação. A classificação avançada das imagens foi através do software WEKA 3.8, que tem como objetivo proceder à análise computacional e estatística dos dados fornecidos recorrendo a técnicas de mineração de dados. Os arquivos das amostras de treinamento foram correlacionados com os arquivos contendo todos os segmentos, empregando o classificador supervisionado avançado Random Forest, e também foi aplicado na metodologia de classificação da plataforma Mapbiomas. A finalização do processo de classificação ocorreu no software Quantum GIS 2.18 (QGIS 2.18) através da substituição dos dados obtidos pela classificação no WEKA 3.8, gerados a partir da segmentação. Em seguida, os arquivos vetorizados gerados pela segmentação foram rasterizados e, definindo uma escala de cores baseadas nas cores impostas pela plataforma Mapbiomas, facilitando assim a interpretação visual das imagens geradas. Ainda no software QGIS 2.18, a detecção de mudanças ocorridas na cobertura e uso do solo foi através da utilização do plugin MOLUSCE, no qual somente é disponibilizado para esta versão. Para isso, foi necessária a rasterização desses arquivos para a utilização. Este complemento tem por objetivo a avaliação de mudanças no uso e cobertura do solo, análise das variações do uso e ocupação do solo em áreas urbanas, bem como em aplicações e projetos de tendência florestal [6]. Definidas como inicial a cena referente ao ano de 2013 e a final referente ao ano de 2019 sobre a mesma projeção cartográfica, o MOLUSCE elabora primeiramente as tabelas alfanuméricas para posterior geração do mapa de mudanças da cobertura do solo, obtendo melhor interpretação visual, sendo possível a comparação entre os resultados. Com o mapa de transição gerado, calcularam-se as áreas de transição entre as classes e quais áreas não sofreram mudanças, através da ferramenta r.report, do QGIS 2.18 with GRASS, onde se calcula a área de cada classe definida no mapa. Na plataforma do Mapbiomas, as transições são separadas por classes. A classe que representada pela cor vermelha apresenta as transições de cobertura florestal ou áreas naturais não florestais para agropecuária ou áreas não vegetadas. Já a classe que representada na cor cinza expressa áreas sem transição ou transições que envolvem áreas não observadas ou transições entre as classes majoritárias do Mapbiomas. A fim de comparação entre os mapas de uso do solo gerados e os disponibilizados pela plataforma Mapbiomas, executou-se a validação das classificações. A validação foi realizada apenas para a época inicial do estudo (2013), pois a plataforma Mapbiomas ainda não havia disponibilizado a imagem classificada referente ao ano de 2019, para a validação desta. A aquisição do mapa de referência foi realizada por meio da plataforma Google Earth Engine. Executando o script disponibilizado pelo Mapbiomas para acesso das coleções da plataforma, definiram-se assim alguns parâmetros a respeito da área de estudo, como o bioma (Amazônia), a Unidade da Federação (Rondônia), o município (Monte Negro), o tipo de dado (cobertura do solo) e por fim o ano do mapa (2013). Após adquirir o mapa referência classificado, gerou-se uma camada contendo uma nuvem de pontos aleatórios sobre a mesma extensão das camadas, que devem pertencer à mesma projeção cartográfica. Utilizou-se a ferramenta vetorial "Unir pontos pelos atributos", do QGIS 2.18, para associar a localização dos pontos gerados com as classes do mapa de referência e do mapa classificado. Para o shapefile de pontos gerados aleatoriamente, realizou-se o cruzamento espacial entre a localização dos pontos e os dados do mapa de referência e da respectiva classificação, gerando uma coluna da tabela de atributos do shapefile de pontos aleatórios associada ao nome da classe daquele ponto na referência, e outra coluna ao nome da classe do mesmo ponto na classificação. A partir desta planilha, gerou-se uma matriz de confusão, através da qual foram calculados a exatidão global, o índice Kappa, e as acurácias do produtor e usuário para cada classe. Por fim, concluídos todos os procedimentos, foram gerados os mapas de uso do solo e mapa de transição, utilizando-se do Compositor de 
Impressão do QGIS 2.18, onde se produziram todos os elementos de mapa possíveis para melhor interpretação visual.

\section{Resultados e Discussão}

Como resultado, obteve-se dois mapas temáticos para as cenas 2013 e 2019 a partir da classificação supervisionada utilizando o classificador avançado Random Forest. Desta forma, foi possível quantificar as áreas desmatadas durante o intervalo temporal em estudo e validar a classificação realizada. As Figuras 2 e 3 representam o mapa do município de Monte Negro classificado para o ano de 2013 e 2019, respectivamente.

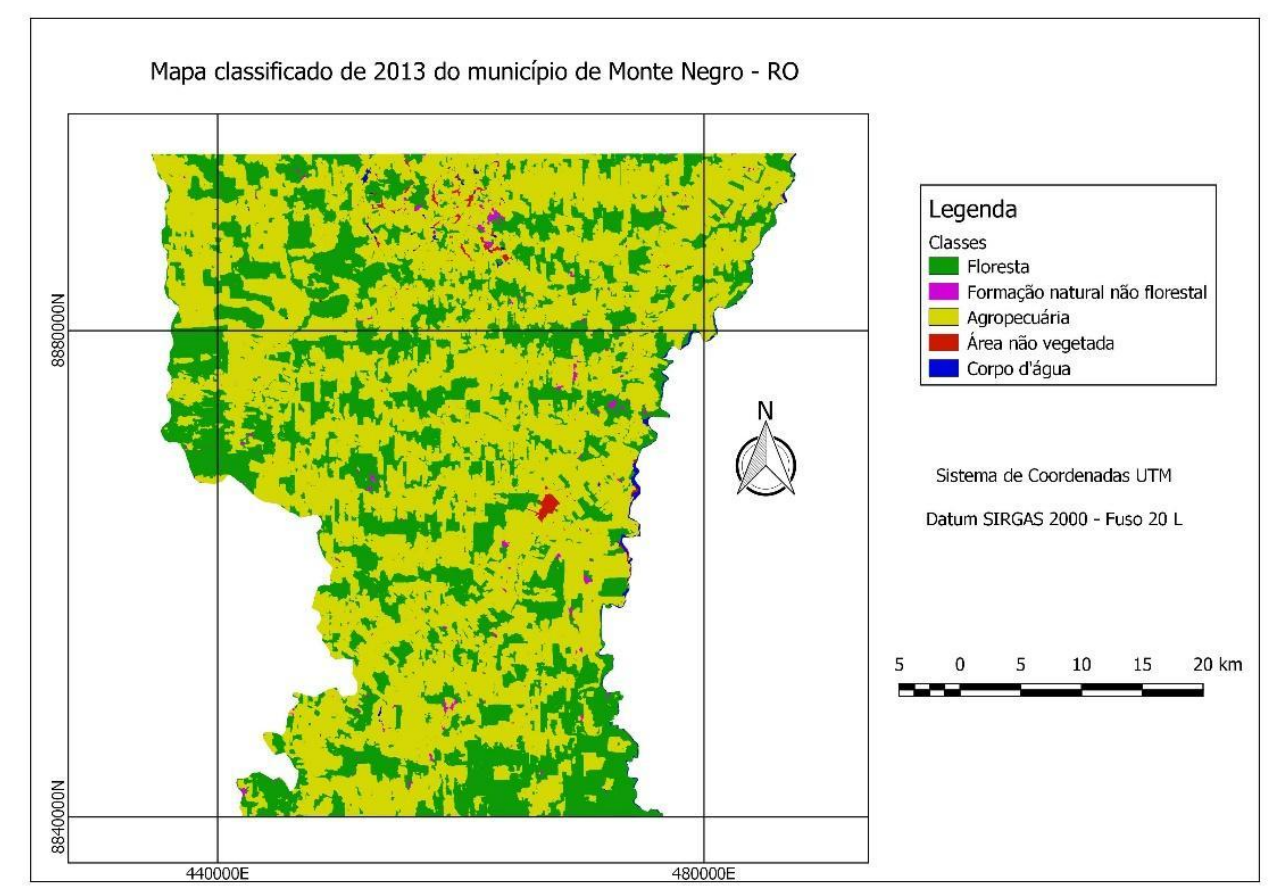

Figura 2. Mapa do município de Monte Negro classificado do ano de 2013.

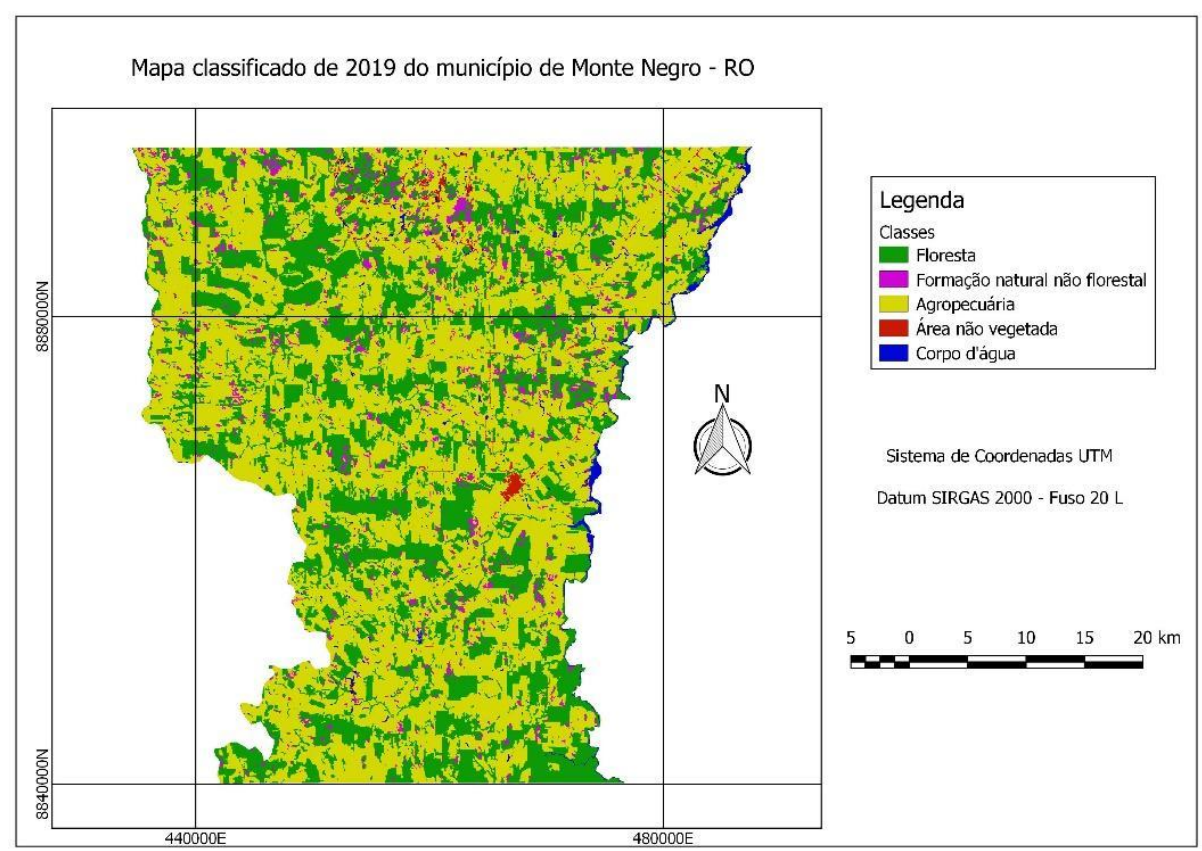

Figura 3. Mapa do município de Monte Negro classificado do ano de 2019. 
A partir dos resultados das classificações e das quantificações das áreas referentes a cada classe, foram obtidos os valores comparativos das áreas de cada classe através do plugin MOLUSCE. A Tabela 1 apresenta a quantificação dessas áreas e a diferença entre elas referente à época inicial do estudo (2013) até a época final do estudo (2019).

Tabela 1. Comparação temporal das mudanças de classes.

\begin{tabular}{l|r|r|r|r|r|r}
\hline Classes & $2013(\mathrm{ha})$ & $2019(\mathrm{ha})$ & $\Delta(\mathrm{ha})$ & \multicolumn{1}{c|}{$\begin{array}{c}2013 \\
(\%)\end{array}$} & $\begin{array}{c}2019 \\
(\%)\end{array}$ & $\Delta(\%)$ \\
\hline Agropecuária & $110.511,760$ & $114.935,610$ & $4.423,85$ & 57,238 & 59,530 & 2,291 \\
\hline Floresta & $76.214,620$ & $66.827,390$ & $-9.387,23$ & 39,474 & 34,612 & $-4,862$ \\
\hline $\begin{array}{l}\text { Formação } \\
\text { natural não } \\
\text { florestal }\end{array}$ & $3.079,800$ & $7.696,980$ & $4.617,18$ & 1,595 & 3,987 & 2,391 \\
\hline $\begin{array}{l}\text { Corpo d'água } \\
\text { Área não } \\
\text { vegetada }\end{array}$ & $1.641,140$ & $2.185,490$ & 544,35 & 0,850 & 1,132 & 0,282 \\
\hline Área Total & $193.075,830$ & $1.427,680$ & $-198,15$ & 0,842 & 0,739 & $-0,103$ \\
\hline
\end{tabular}

De acordo com a Tabela 1, foram gerados os valores referentes às áreas de cada classe em relação aos anos de 2013 e 2019 e também as variações entre os períodos. Estes valores foram disponibilizados tanto em grandeza métrica, quanto em porcentagem. Observa-se que a maior área contida no município, com quase $60 \%$ de ocupação, refere-se à classe agropecuária, cujo valor foi aumentado na comparação temporal em 3,84\%, equivalente a 4.423 hectares. Enquanto a classe floresta teve uma redução de área equivalente a 12,31\%, equivalente a 9.387 hectares. Além de apresentar as quantificações de cada classe, o MOLUSCE disponibilizou-se também uma matriz de transição das áreas em porcentagem de pixels, no qual foi convertida para hectares para maior compreensão. Essa matriz, apresentada na Tabela 2 apresenta as áreas das classes, em hectares, que sofreram transições e que se mantiveram na mesma classe, sendo possível realizar a quantificação da área desmatada, baseando-se na metodologia da plataforma Mapbiomas. Essas áreas foram calculadas através da ferramenta r.report do QGIS 2.18.

Tabela 2. Matriz de transição dos pixels entre as classes no intervalo temporal em estudo.

\begin{tabular}{|c|c|c|c|c|c|c|c|}
\hline & & \multicolumn{5}{|c|}{2019 (ha) } & \multirow{2}{*}{$\begin{array}{l}\text { Área } \\
\text { Total } \\
(2013)\end{array}$} \\
\hline & CLASSES & Floresta & $\begin{array}{c}\text { Agropecuári } \\
\text { a }\end{array}$ & $\begin{array}{l}\text { Formação } \\
\text { não } \\
\text { florestal }\end{array}$ & $\begin{array}{l}\text { Área não } \\
\text { vegetada }\end{array}$ & $\begin{array}{l}\text { Corpo } \\
\text { d'água }\end{array}$ & \\
\hline $\begin{array}{l}2 \\
0\end{array}$ & Floresta & $56.297,67$ & $16.064,90$ & $3.431,32$ & 41,37 & 409,46 & $76.244,72$ \\
\hline
\end{tabular}




\begin{tabular}{|c|c|c|c|c|c|c|c|}
\hline $\begin{array}{l}1 \\
3\end{array}$ & Agropecuária & $9.483,16$ & $96.887,71$ & $2.794,49$ & 694,30 & 628,90 & $\begin{array}{r}110.488,5 \\
6\end{array}$ \\
\hline h & $\begin{array}{l}\text { Formação } \\
\text { não florestal }\end{array}$ & 950,11 & 748,24 & $1.347,82$ & 2,53 & 34,31 & $3.083,01$ \\
\hline ) & $\begin{array}{l}\text { Área não } \\
\text { vegetada }\end{array}$ & 22,56 & 830,42 & 21,53 & 608,65 & 143,19 & $1.626,35$ \\
\hline & Corpo d'água & 78,00 & 405,65 & 108,12 & 79,28 & 971,33 & $1.642,38$ \\
\hline & $\begin{array}{l}\text { Área Total } \\
(2019)\end{array}$ & $66.831,50$ & $114.936,92$ & $7.703,28$ & $1.426,13$ & $2.187,19$ & $\begin{array}{r}193.085,0 \\
2\end{array}$ \\
\hline
\end{tabular}

Após a obtenção desses resultados, gerou-se o mapa de transição da cobertura do solo entre as imagens. A Figura 4 apresenta o mapa das mudanças ocorridas na cobertura do solo, gerado a partir das classificações realizadas nas imagens de cada época através do plugin MOLUSCE.

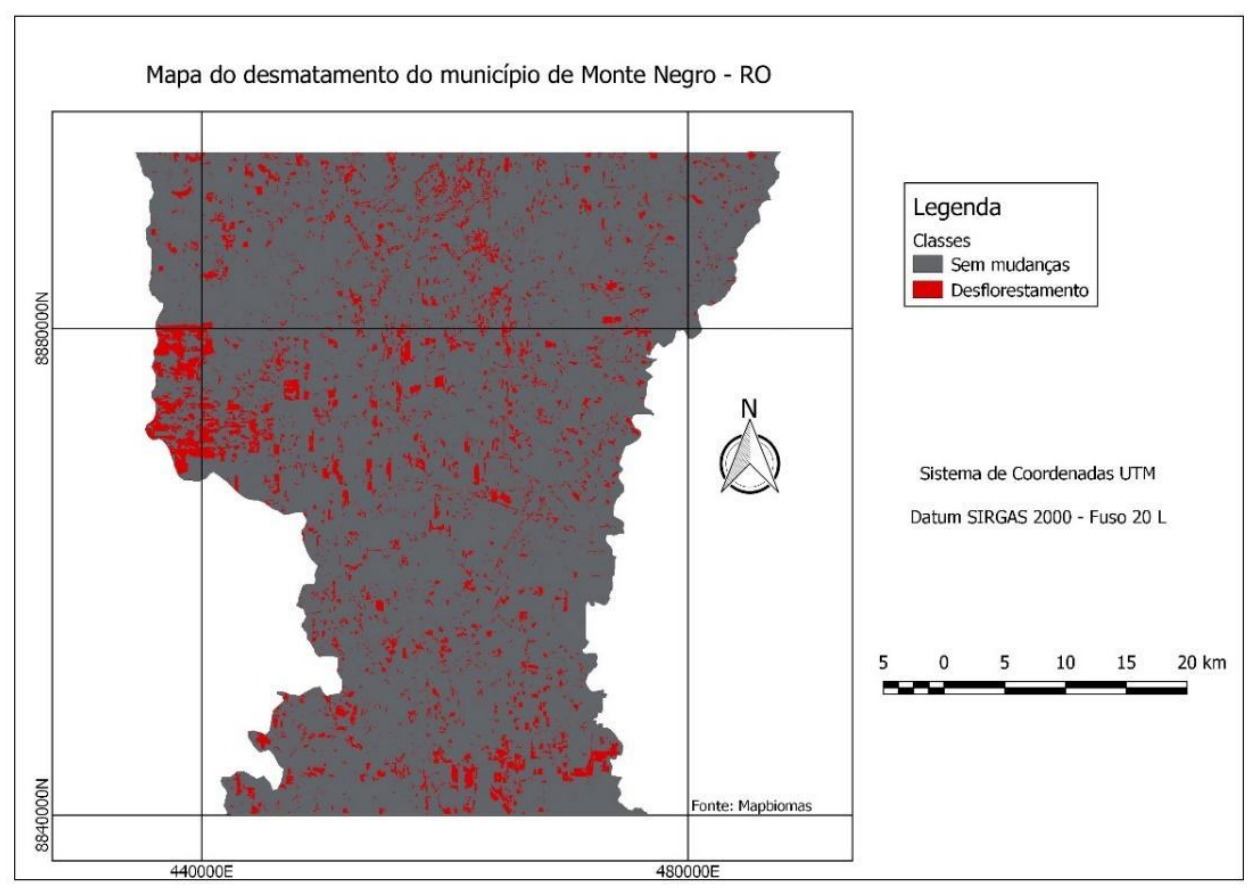

Figura 4. Mapa do desflorestamento ocorrido sobre a área de estudo.

De acordo com a Figura 4, a definição das cores e as transições entre as classes que compõem a quantificação do desflorestamento, basearam-se em relação à plataforma do Mapbiomas. A cor vermelha representa as áreas desmatadas entre os anos de 2013 e 2019 acumulados, enquanto a cor cinza refere-se às áreas que não sofreram transições relacionadas ao desmatamento. A partir do mapa de transição, quantificaram-se as áreas em transição através do plugin r.report, organizando esses valores em tabelas e gerando gráficos para melhor análise dos dados. As transições consideradas como desmatamento, são das classes Floresta ou Formação natural não florestal, para as classes Agropecuária ou Área não vegetada. A Tabela 3 demonstra os valores das áreas desmatadas, das áreas que não sofreram transição de classes, e a área total do município, calculadas através do r.report. 
Tabela 3. Quantificação da área desmatada, área sem mudança e área total do município.

\begin{tabular}{c|c|c}
\hline Classificação & Área (ha) & Área (\%) \\
\hline Área sem mudanças & $175.714,21$ & 91,00 \\
\hline Área desmatada & $17.370,81$ & 9,00 \\
\hline Área Total & $193.085,02$ & 100 \\
\hline
\end{tabular}

De acordo com a Tabela 3, a área que permaneceu inalterada equivale a $91,00 \%$ (175.714,21 ha) da área total do local de estudo, sendo então área desmatada cerca de $9,00 \%(17.370,81 \mathrm{ha})$ da área total. A partir da geração da nuvem de pontos aleatórios, no qual foram gerados 701 pontos sobre a área de estudo para a validação da cena classificada de 2013 em relação ao mapa de referência obtido pelo Mapbiomas, foi possível gerar a matriz de confusão e calcular o percentual de pontos corretamente classificados. Como resultado, a validação da classificação dos dados, utilizando o classificador Random Forest, foi realizada nos mapas referentes ao ano de 2013 e apresentou uma Exatidão Global de 72,90\%. Também foi possível calcular os índices de exatidão para cada classe conforme apresentado na Tabela 4.

Tabela 4. Índices da avaliação da exatidão.

\begin{tabular}{c|c|c|c|c}
\hline Avaliação da Exatidão & $\begin{array}{c}\text { Exatidão do } \\
\text { Produtor da } \\
\text { classe }\end{array}$ & $\begin{array}{c}\text { Erro de } \\
\text { omissão da } \\
\text { classe }\end{array}$ & $\begin{array}{c}\text { Exatidão do } \\
\text { Usuário da } \\
\text { classe }\end{array}$ & $\begin{array}{c}\text { Erro de } \\
\text { inclusão da } \\
\text { classe }\end{array}$ \\
\hline Floresta & $73,80 \%$ & $26,20 \%$ & $58,89 \%$ & $41,11 \%$ \\
\hline $\begin{array}{c}\text { Formação natural não } \\
\text { florestal }\end{array}$ & $80,00 \%$ & $20,00 \%$ & $44,44 \%$ & $55,56 \%$ \\
\hline Agropecuária & $72,53 \%$ & $27,47 \%$ & $85,27 \%$ & $14,73 \%$ \\
\hline Área não vegetada & $50,00 \%$ & $50,00 \%$ & $33,33 \%$ & $66,67 \%$ \\
\hline Corpo d'água & $83,33 \%$ & $16,67 \%$ & $55,56 \%$ & $44,44 \%$ \\
\hline
\end{tabular}

Os dados da Tabela 4 mostram que a Exatidão do Produtor teve uma representatividade média de $72 \%$, o que significa que as amostras coletadas sobre a base de referência do Mapbiomas tiveram uma alta eficácia. A classe Corpo d'água foi a que obteve o maior valor de Exatidão do Produtor, correspondendo a 83,33\%. $\mathrm{Na}$ Exatidão do Usuário as classes tiveram uma representatividade média de 55,5\%, o que significa que a maior parte das amostras coletadas foi classificada corretamente. A classe Agropecuária foi a que obteve o maior valor de Exatidão do Usuário, correspondendo a $85,27 \%$. Comparando os coeficientes de concordância, a classe Agropecuária foi a que obteve um maior índice de avaliação de exatidão.

\section{Conclusão}

Com o uso do geoprocessamento e de imagens orbitais de domínio público, notam-se as mudanças ocorridas na cobertura do solo, de forma confiável e satisfatória. Ao longo do período de avaliação (2013-2019), constatou-se que 9\% da área total do 
município de Monte Negro - RO foi desmatada. Nesse processo, averiguou-se, principalmente, a conversão de floresta em agropecuária. Isso significa que houve um aumento da prática pecuarista, interferindo na biodiversidade da região.

Observa-se que a maior transição ocorrida em relação às áreas originais foi na classe floresta, correspondendo a 92,48\% (16.064,90 ha) do desmatamento total ocorrido sobre a área de estudo. É importante destacar que o presente trabalhou realizou a análise para uma única data de 2013, e desta maneira já era esperada certa variação entre o produto gerado e o disponibilizado pelo Mapbiomas. A classificação na área estudada apresentou uma Exatidão Global superior a $70 \%$, o que indica um bom desempenho do classificador quando comparado ao mapa de referência. Essa análise só foi possível para o ano de 2013, visto que o Mapbiomas ainda não disponibilizou o mapa de 2019. De acordo com o estudo realizado e os resultados obtidos, através do geoprocessamento e de técnicas de sensoriamento remoto, foi possível quantificar a área desmatada no município de Monte Negro, em Rondônia, entre os anos de 2013 e 2019. Como sugestão para trabalhos futuros, a classificação gerada para o ano de 2019 poderá ser comparada com a base de dados do Mapbiomas a ser disponibilizada, ou ainda, ter o período de análise estendida de 1985 a 2018, épocas que o Mapbiomas possui uma base de dados.

\section{Referências}

[1] Brasil. Lei Complementar № 124, de 3 de janeiro de 2007. Institui, na forma do art. 43 da Constituição Federal, a Superintendência do Desenvolvimento da Amazônia SUDAM; estabelece sua composição, natureza jurídica, objetivos, área de competência e instrumentos de ação; e dá outras providências, 2007. Disponível em: $<$ https://bit.ly/2NmbUqb>. Acesso em: 03 de mar. 2020.

[2] Araujo L.C.L., Souza J.J., Morais V.M.C., Souza A.A.A., Oliveira R.R.S., Gomes A. R., Narvaes I.S., Adami M. Avaliação das alterações na cobertura florestal utilizando dados de projetos de monitoramento do desmatamento da Amazônia e verificação em campo: estudo de caso para o trecho Belém a Rurópolis - PA. Anais do XIX Simpósio Brasileiro de Sensoriamento Remoto, Santos, Abril 2019. ISSN 978-85-17-00097-3. Disponível em: <https://bit.ly/376JIEt>. Acesso em: 07 de mar. 2020.

[3] Maurano L.E.P., Escada M.I.S. Comparação dos dados produzidos pelo PRODES versus dados do Mapbiomas para o bioma Amazônia. Anais do XIX Simpósio Brasileiro de Sensoriamento Remoto, Santos, p. 735, abr. 2019. Disponível em $<$ https://bit.ly/2OvEmqn>. Acesso em: 03 de mar. 2020.

[4] Projeto Radambrasil. Folha SC. 20 Porto Velho: geologia, geomorfologia, pedologia, vegetação, uso potencial da terra, Rio de Janeiro, v. 16, 2003. ISSN 2401003900. Disponível em: <https://bit.ly/2LFwDF2>. Acesso em: $11 \mathrm{de} \mathrm{fev.} 2020$.

[5] Rouse J.W., Jr. Haas R.H., Schell J.A., Deering D.W. Monitoring Vegetation Systems in the Great Plains with ERTS. Third Earth Resources Technology Satellite-1 Symposium. Volume 1: Technical Presentations, section A. Greenbel, Maryland, USA., 1973. Disponível em: <https://bit.ly/3cXFH3s>. Acesso em: 05 de mar. 2020.

[6] Holler W.A., Rosot M.A.D., Franciscon L., Garrastazú M.C., Oliveira Y.M.M., Maran J.C. Como proceder na detecção de mudanças de uso e cobertura da terra. EMBRAPA, Colombo, Outubro 2018. ISSN 1980-3982. Disponível em: <https://bit.ly/3rD6JkC>. Acesso em: 11 de fev. 2020. 


\section{Autores}

Cayo Guimarães Machado ${ }^{1, *}$, Camila Souza dos Anjos Lacerda², Carolina Gil Garcia ${ }^{3}$, Débora Paula Simões ${ }^{2}$

1. Instituto Federal de Educação, Ciência e Tecnologia do Sul de Minas - Campus Inconfidentes, Praça Tiradentes, 416 - Centro, 37576-000, Inconfidentes, Brasil.

2. Departamento de Agrimensura e Cartografia, Instituto Federal de Educação, Ciência e Tecnologia do Sul de Minas - Campus Inconfidentes, Praça Tiradentes, 416 - Centro, 37576-000, Inconfidentes, Brasil.

3. Departamento de Meio Ambiente, Instituto Federal de Educação, Ciência e Tecnologia do Sul de Minas - Campus Inconfidentes, Praça Tiradentes, 416 Centro, 37576-000, Inconfidentes, Brasil.

* Autor para correspondência: cayoeacif@gmail.com 